\title{
SURVEILLANCE OF ESCHERICHIA COLI IN A FISH FARM OF SYLHET, BANGLADESH
}

\author{
Rizoneul Haq Reza1 ${ }^{1}$, Shahena Aktar Shipa1 ${ }^{1}$ M. Niamul Naser ${ }^{2}$ \\ and Md. Faruque Miah*1 \\ Zoology, Fisheries and Marine Biotechnology Research Unit, Department of \\ Genetic Engineering and Biotechnology, Shahjalal University of Science and \\ Technology, Sylhet, Bangladesh
}

\begin{abstract}
The study was accomplished to investigate Escherichia coli from two freshwater fish, Tilapia (Oreochromis niloticus) and Mrigal (Cirrhinus mrigala), collected from a fish farm in Sylhet, Bangladesh. Six of each fish were analyzed to isolate and detect Escherichia coli, and E. coli was identified based on morphological and biochemical characteristics. The antibiogram of $E$. coli was investigated in different generations using eight antibiotic discs such as Chloramphenicol $(\mathrm{CH})$, Streptomycin (S), Gentamycin (G), Ciprofloxacin (CI), Cotrimethoxazole (CO), Azithromycin (AZI), Erythromycin (E) and Novobiocin (NV), and the sensitivity of $E$. coli was found as 100\%, 25\%, 100\%, 75\%, 87.5\%, $81.25 \%, 0 \%, 0 \%$ respectively. Among the 8 antibiotics, for Erythromycin (E) and Novobiocin (NV), the observed resistance pattern of E. coli was $81.25 \%$ and $87.5 \%$ respectively, whereas, for the rest of the antibiotics, it was $0 \%$.
\end{abstract}

Key words: freshwater, aquaculture, Escherichia coli, antibiotic resistance

\section{INTRODUCTION}

Bangladesh is rich in fisheries resources and recognized as the third aquaculture country in the world (FAO 2018), including vast culture potential where the inland aquaculture sector is contributing more than $55 \%$ of the total production of Bangladesh (DoF 2016). Among 266 freshwater fish including16 exotic species, around 25 species are being cultured (IUCN 2014, FRSS 2016). Freshwater aquaculture is mainly comprised of pond farming in Bangladesh where Tilapia (Oreochromis niloticus) and Mrigal (Cirrhinus mrigala) are commonly cultured species. However, among the other causes, diseases are responsible for the huge loss of production in aquaculture, especially in developing countries as they contain $90 \%$ of the aquaculture farm. For example, in Chile, 2 billion dollars lost caused by infectious salmon anemia alone and

*Author for Corresponding: <faruque-btc@sust.edu>, 2Department of Zoology, University of Dhaka, Dhaka 1000, Bangladesh.

@2020 Zoological Society of Bangladesh DOI: https://doi.org/ 10.3329/ bjz.v48i2.52373 
$15 \%$ loss of total fish production to diseases in China (Leung et al. 2013 and Assefa et al. 2018).

Different pathogenic bacteria are involved to impact the fish production in Bangladesh whereas few fecal coliforms were observed (Mandal et al. 2009) as a fish pathogen that often contaminants of food and water through $E$. coli is mostly non-pathogenic (Dutta et al. 2010, Soliman et. al. 2010, Eze et al. 2011). Generally, for the potential sewage pollution, based on strains, E. coli present in fish are considered as an indicator (Hanson et al. 2008). Inside the intestine of fish, E. coli commonly resident as non-pathogenic but when expanding outside the intestine, it can be responsible for causing disease, resulting in enterotoxigenic (Lee and Marks 2009) whereas 18 toxigenic E. coli were isolated (Vieira et al. 2001). The sensitivity of different antibiotics was examined and found high effect against $E$. coli isolates from fish samples (Sukumaran et al. 2012, Soliman et al. 2010). The reason for the versatility of $E$. coli strains of involving different strains with different diseases is because they obtaining virulence genes of different sets. E. coli strains are related with different disease-causing fish virulence genes as well (Teophilo et al. 2002, Gupta et al. 2013).

As a remarkable number of fish species are available in the freshwater of Bangladesh, tilapia (O. niloticus) and mrigal (C. mrigala) contribute an important role in nutrition as well as the national economy. Though few researches observed the occurrence of fecal coliform mostly in E. coli of Nile tilapia (Thampuran et al. 2005, Mandal et al. 2009). However, information is not available for mrigal (C. mrigala) in Bangladesh. Due to the high economic value of these two fishes in Bangladesh, this research is aimed to observe the status of fecal coliform in a farm condition of Sylhet and to know the surveillance of $E$. coli in terms of occurrence, detection, and antibiogram assay.

\section{MATERIAL AND METHODS}

Sample collection: The study was conducted in the Department of Genetic Engineering and Biotechnology (GEB) at Shahjalal University of Science and Technology (SUST), Sylhet, Bangladesh. Total 12 fish of Tilapia (Oreochromis niloticus) and Mrigal (Cirrhinus mrigala), 6 for each were collected from a farming pond of Sylhet, Bangladesh, which then immediately transported to the Zoology, Fisheries and Marine Biotechnology Research Unit in the Department of GEB, SUST for further studies. Fish samples were identified according to the morphometric characteristics (Shafi and Quddus 1982, Rahman 1989) and E. coli was isolated from the liver, heart, gills, scales surface, and fin of the fish samples. 
Preparation of experimental materials: The isolation of the bacteria from experimental fish and identification of $E$. coli isolates was performed using morphological and biochemical characteristics. All materials like Petri dishes, test tubes, stock bottles, etc. were washed with detergent and dried at $70^{\circ} \mathrm{C}$ in an oven drier and sterilized at $170^{\circ} \mathrm{C}$ for 1.5 hours by a hot air sterilizer. The tips were washed and autoclaved at $121^{\circ} \mathrm{C}$ for 15 minutes. Then the glassware was again put into a drier at $70^{\circ} \mathrm{C}$ before use. Most of the sterilization processes were followed according to the instructions described by Barrow and Feltham (1993).

Isolation of $E$. coli by selective culture media: First of all, 51.53 grams of MacConkey agar was added to a flask containing $1000 \mathrm{ml}$ of distilled water, and to dissolve the medium completely, the heat was applied until the boiling. Through the autoclave, the medium was subjected to sterilization. Furthermore, 38 grams of EMB agar base (Himedia, India) also added to a flask containing $1000 \mathrm{ml}$ of distilled water and for a fine mixture, the heat was applied. Again, for sterilizing the medium, autoclave was done at $121^{\circ} \mathrm{C}(15 \mathrm{psi})$ for 15 minutes and then, to lowering the temperature of the medium, it was placed into a water bath of $45^{\circ} \mathrm{C}$. When the medium was solidified, to confirm the sterility, the Petri dishes were kept incubated at $37^{\circ} \mathrm{C}$ overnight and then stored at $4^{\circ} \mathrm{C}$ in the refrigerator until used. The samples collected were placed on a MacConkey agar plate by using a sterile loop and cultured on the medium by the streaked plate technique, which were then incubated at $37^{\circ} \mathrm{C}$ for 24 hours. The appearance of the colonies a characteristic green metallic sheen with a dark center was considered positive for $E$. coli.

Performance of pure culture of E. coli: About $500 \mathrm{ml}$ of Nutrient Agar (NA) medium was prepared followed by Cappuccino and Sherman (2007) and stirred by a magnetic stirrer. Following the previous autoclave procedure, the medium was sterilized and after reducing the temperature of the medium up to $60^{\circ} \mathrm{C}$, it was poured into sterile Petri dishes with the amount of $25 \mathrm{ml}$ each, which are then kept for future use after the solidifying of the plates. A single colony was taken from EMB agar plate by using sterile loop and inoculated on the NA medium. The plates were then incubated at $37^{\circ} \mathrm{C}$ for 24 hours.

Morphological Identification of E. coli strains: The bacterial colonies grown on agar medium were recorded for their colony characteristics such as size, shape, the color of the colony. Morphological characters of the isolates such as shape and size were recorded during Gram's staining procedure with the fresh subculture of 24 hours and recorded accordingly. To differentiate the motile bacteria from the non-motile ones, the motility test was done followed by the 
method mentioned by Cowan (1985) where observing the movement of bacteria, motility were identified.

Gram staining was conducted followed by the method described by Petersen et al. (2016) using a compound microscope.

Biochemical identification of E. coli isolates: For the verification of E. coli, the biochemical tests performed were Voge's Proskauer (VP) test, methyl red (MR) test, Catalase test, TSI test, Oxidase test, urease activity test, lactose fermentation tests, indole test, and Citrate utilization test. E. coli were distinguished by their ability to ferment lactose, positive for indole test and MR test and negative for VP, urease activity, Oxidase test, and Citrate utilization test.

Preservation of bacterial isolates in pure culture form: To use the prepared pure culture as a stock culture, it was stored at $-20^{\circ} \mathrm{C}$ after adding equal volume of $80 \%$ glycerin.

Detection of Antimicrobial Sensitivity Patterns: Kirby-Bauer method of antibiotic susceptibility testing (AST) was used to study E. coli which is known as the disk diffusion method as well. In this experiment, we used the discs produced by Himedia Laboratories Pvt. Limited, Mumbai. The procedure of the antimicrobial sensitivity was used for 15 isolated $E$. coli.

Susceptibility test of identified E. coli and ATCC was done on Mueller Hinton Agar and 8 different antibiotic discs such as Streptomycin, Erythromycin, Gentamycin, Chloramphenicol, Ciprofloxacin, Co-trimethxazole, Azithromycin, and Novobiocin were used. After preparing the media with proper manufacture's instruction, it was sterilized by autoclaving. Sterilized Petri dishes containing media were allowed to solidify. The fresh nutrient broth was prepared and a volume of $6-8 \mathrm{ml}$ was dispensed in each test tube which then sterilized by autoclaving. Identified E. coli and ATCC strains were then inoculated with a sterilized loop from pure culture and were incubated for 24 hours at $37^{\circ} \mathrm{C} . \mathrm{OD}_{600}$ was measured by using a spectrophotometer for keeping the same bacterial density and the $\mathrm{OD}_{600}$ of broth cultures were adjusted at 0.24 by serial dilution method. By using L shaped glass rod, 100 microliters of microbial inoculums from the diluted nutrient broth was poured and spread throughout the surface of Mueller Hinton Agar. The antibiotic disc was set on the surface of the ager, with the help of a sterilized needle at a maximum distance for getting distinct zones. The Petri dishes were then subjected for incubation at $37{ }^{\circ} \mathrm{C}$ for $12-18$ hours. In this method ATCC strain (25922) was used as a reference. By analysis with the standard table for the zone of inhibition, all the results were detected. The Petri dishes were examined after 12-18 hours and then calculated the zone 
of complete inhibition ( $\mathrm{mm}$ in diameter). From the analyzed data, we can get the $\%$ of resistance, intermediate, and sensitivity pattern of the identified E. coli.

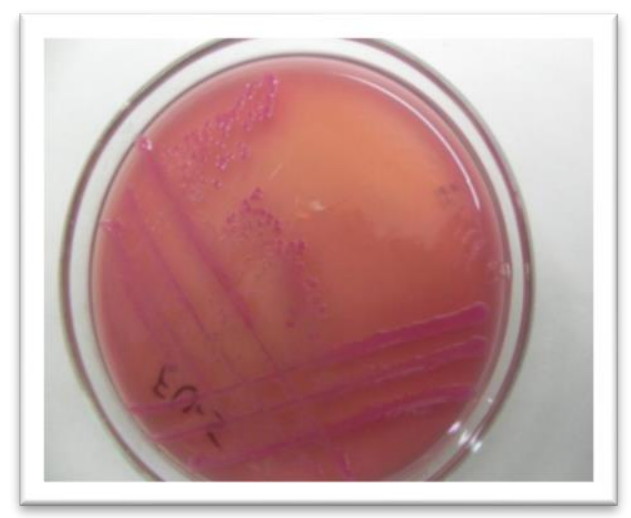

(a)

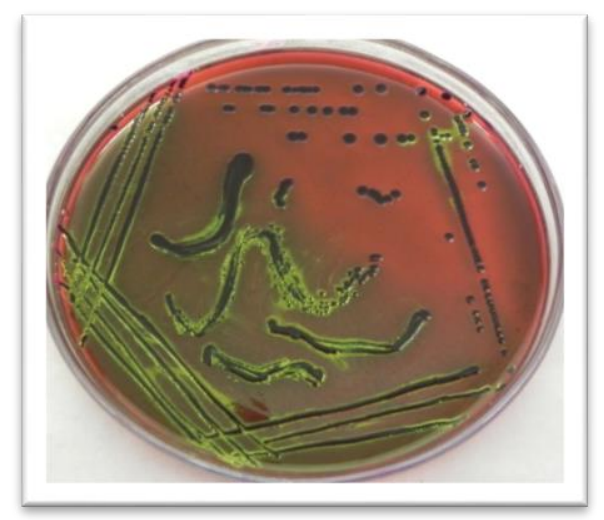

(b)

Fig.1: Identification of E. coli: (a) E. coli culture on Mac Conkey's agar plate; b) E. coli culture on EMB agar plate.

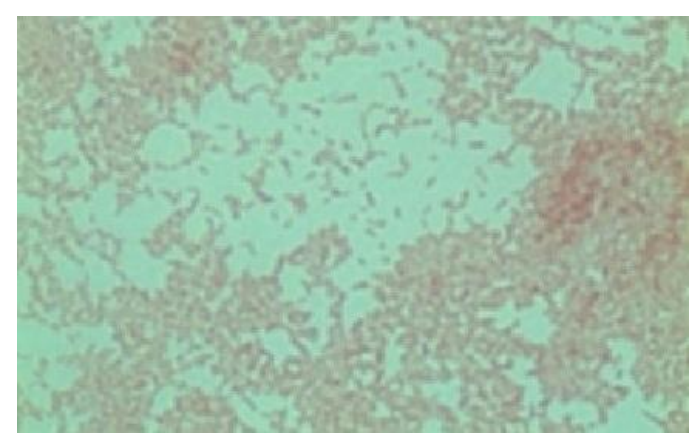

Fig. 2: Gram's staining of bacterial isolates showing Gram-negative, small rod-shaped, pink coloredand single or paired organisms

\section{RESULTS AND DISCUSSION}

Isolation and identification of E. coli: A total number of 12 fish samples were collected from the different markets of Sylhet city and then screened for the confirmation of E. coli (Fig. 1). All the examined Tilapia and Mrigal samples were found positive with E. coli. A total 21 of $E$. coil isolates were isolated from 12 experimental fish samples. On the basis of samples examined, the incidence of E. coli varies.

Motility test: Twenty-one isolates were found motile in the motility test. 
Gram's stain: In Gram's staining, the organism showed gram-negative, small rod-shaped, pink color, and single or paired arrangement characteristics (Fig. 2) under the microscope.

Biochemical tests: For the suspected bacteria, several biochemical tests were conducted for characterization. All biochemical test results are given in Table 1.

Table 1. Biochemical test for $E$. coli identification

\begin{tabular}{|c|c|c|c|c|c|c|c|c|c|c|c|}
\hline Sample code & M & $\mathrm{G}$ & MR & VP & $\mathrm{C}$ & TSI & $\mathrm{O}$ & $\mathrm{U}$ & $\mathrm{LF}$ & IT & $\mathrm{CU}$ \\
\hline E-1 & + & - & + & - & + & + & - & - & + & + & - \\
\hline E-2 & + & - & + & - & + & + & - & - & + & + & - \\
\hline E-3 & + & - & + & - & + & + & - & - & + & + & - \\
\hline E-4 & + & - & + & - & + & + & - & - & + & + & - \\
\hline E-5 & + & - & + & - & + & + & - & - & + & + & - \\
\hline E-6 & + & - & + & - & + & + & - & - & + & + & - \\
\hline E-7 & + & - & + & - & + & + & - & - & + & + & - \\
\hline E-8 & + & - & + & - & + & + & - & - & + & + & - \\
\hline E-9 & - & + & - & - & + & - & + & - & + & - & - \\
\hline E-10 & + & - & + & - & + & + & - & - & + & + & - \\
\hline E-11 & + & - & + & - & + & + & - & - & + & + & - \\
\hline E-12 & + & - & + & - & + & + & - & - & + & + & - \\
\hline E-13 & + & - & + & - & + & + & - & - & + & + & - \\
\hline E-14 & + & - & + & - & + & + & - & - & + & + & - \\
\hline E-15 & + & - & + & - & + & + & - & - & + & + & - \\
\hline E-16 & + & - & + & - & + & + & - & - & + & + & - \\
\hline E-17 & - & - & + & + & - & + & - & + & - & + & + \\
\hline E-18 & + & - & + & - & + & + & - & - & + & + & - \\
\hline E-19 & + & + & - & + & - & + & + & - & - & - & + \\
\hline E-20 & - & - & + & + & - & - & + & + & - & - & + \\
\hline E-2 1 & - & + & - & - & + & - & - & + & - & + & + \\
\hline
\end{tabular}

$\mathrm{M}=$ Motility, $\mathrm{G}=\mathrm{Gram}$ test, $\mathrm{MR}=$ Methyl Red test, $\mathrm{VP}=$ Voge's-Proskauer, $\mathrm{C}=$ Catalase test, $\mathrm{TSI}=$ Triple Sugar Iron, $\mathrm{O}=$ Oxidase test, $\mathrm{U}=$ Urease Activity, $\mathrm{LF}=$ Lactose Fermentation Test, IT= Indole Test, $\mathrm{CU}=$ citrate agar test.

Presumptive result: To analysis, all E. coli isolates, it was confirmed that E1, E2, E3, E4, E5, E6, E7, E8, E10, E11, E12, E13, E14, E15, E16, and E18 isolates were E. coli. E. coli was observed as Oxidase negative, Catalase positive, Gram-negative, Indole test positive, MR positive, VP negative, and TSI (Triple Sugar Iodine Agar) test positive. List of presumptive E. coli isolates was identified according to Bergey's (1994) and Cowan \& Steel (1974).

Determination of antibiotic sensitivity pattern: 16 isolates were screened for drug resistance profile. All the isolates showed the highest degree of sensitivity against the commonly used antibiotics (Table 2). E. coli ATCC strain was found 
to be highly sensitive against the used antibiotics. Table 3 showed the Standard clear zone diameters for Enterobacteriaceae and table 4 showed the result of this research. The result investigate that sensitivity pattern of $E$. coli for 8 antibiotics \{Chloramphenicol $(\mathrm{CH})$; Streptomycin (S); Gentamycin (G); Ciprofloxacin (CI); Co-trimethoxazole (CO); Azithromycin (AZI); Erythromycin (E); Novobiocin (NV)\} were respectively $100 \%, 25 \%, 100 \%, 75 \%, 87.5 \%, 81.25 \%, 0 \%, 0 \%$. Whereas resistance patterns of $E$. coli for 8 antibiotics were $81.25 \%$ and $87.5 \%$ for Erythromycin (E) and Novobiocin (NV) respectably. The resistance pattern of $E$. coli for the rest of the 6 antibiotics was $0 \%$ to all. On the other hand, intermediate pattern of $E$. coli for 8 \{Chloramphenicol $(\mathrm{CH})$; Streptomycin (S); Gentamycin (G); Ciprofloxacin (CI); Co-trimethoxazole (CO); Azithromycin (AZI); Erythromycin (E); Novobiocin (NV) \} antibiotics were respectively $0 \%, 75 \%, 0 \%$, $25 \%, 12.5 \%, 18.75 \%, 18.75 \%, 12.5 \%$.

Table 2. Antibiotic sensitivity and resistance pattern of isolated $E$. coli by measuring zone diameter of inhibition

\begin{tabular}{lllllllll}
\hline Sample code & S & E & G & CH & CI & CO & AZI & NV \\
& & & & & & & & \\
\hline E-1 & $15 \mathrm{~mm}$ & 15 & $23 \mathrm{~mm}$ & $25 \mathrm{~mm}$ & $21 \mathrm{~mm}$ & $26 \mathrm{~mm}$ & $18 \mathrm{~mm}$ & $\mathrm{NZ}$ \\
E-2 & $20 \mathrm{~mm}$ & $6 \mathrm{~mm}$ & $20 \mathrm{~mm}$ & $22 \mathrm{~mm}$ & $24 \mathrm{~mm}$ & $20 \mathrm{~mm}$ & $20 \mathrm{~mm}$ & $6 \mathrm{~mm}$ \\
E-3 & $18 \mathrm{~mm}$ & $\mathrm{NZ}$ & $22 \mathrm{~mm}$ & $25 \mathrm{~mm}$ & $20 \mathrm{~mm}$ & $22 \mathrm{~mm}$ & $19 \mathrm{~mm}$ & $12 \mathrm{~mm}$ \\
E-4 & $20 \mathrm{~mm}$ & $14 \mathrm{~mm}$ & $24 \mathrm{~mm}$ & $20 \mathrm{~mm}$ & $28 \mathrm{~mm}$ & $18 \mathrm{~mm}$ & $22 \mathrm{~mm}$ & $\mathrm{NZ}$ \\
E-5 & $19 \mathrm{~mm}$ & $10 \mathrm{~mm}$ & $21 \mathrm{~mm}$ & $27 \mathrm{~mm}$ & $22 \mathrm{~mm}$ & $14 \mathrm{~mm}$ & $16 \mathrm{~mm}$ & $\mathrm{NZ}$ \\
E-6 & $22 \mathrm{~mm}$ & $\mathrm{NZ}$ & $20 \mathrm{~mm}$ & $22 \mathrm{~mm}$ & $25 \mathrm{~mm}$ & $24 \mathrm{~mm}$ & $18 \mathrm{~mm}$ & $8 \mathrm{~mm}$ \\
E-7 & $20 \mathrm{~mm}$ & $16 \mathrm{~mm}$ & $21 \mathrm{~mm}$ & $28 \mathrm{~mm}$ & $28 \mathrm{~mm}$ & $18 \mathrm{~mm}$ & $20 \mathrm{~mm}$ & $\mathrm{NZ}$ \\
E-8 & $20 \mathrm{~mm}$ & $\mathrm{NZ}$ & $22 \mathrm{~mm}$ & $22 \mathrm{~mm}$ & $24 \mathrm{~mm}$ & $28 \mathrm{~mm}$ & $18 \mathrm{~mm}$ & $10 \mathrm{~mm}$ \\
E-10 & $22 \mathrm{~mm}$ & $\mathrm{NZ}$ & $24 \mathrm{~mm}$ & $23 \mathrm{~mm}$ & $20 \mathrm{~mm}$ & $20 \mathrm{~mm}$ & $20 \mathrm{~mm}$ & $\mathrm{NZ}$ \\
E-11 & $18 \mathrm{~mm}$ & $6 \mathrm{~mm}$ & $20 \mathrm{~mm}$ & $26 \mathrm{~mm}$ & $23 \mathrm{~mm}$ & $16 \mathrm{~mm}$ & $18 \mathrm{~mm}$ & $13 \mathrm{~mm}$ \\
E-12 & $17 \mathrm{~mm}$ & $\mathrm{NZ}$ & $23 \mathrm{~mm}$ & $26 \mathrm{~mm}$ & $20 \mathrm{~mm}$ & $20 \mathrm{~mm}$ & $21 \mathrm{~mm}$ & $\mathrm{NZ}$ \\
E-13 & $18 \mathrm{~mm}$ & & $20 \mathrm{~mm}$ & $24 \mathrm{~mm}$ & $26 \mathrm{~mm}$ & $15 \mathrm{~mm}$ & $17 \mathrm{~mm}$ & $\mathrm{NZ}$ \\
E-14 & $22 \mathrm{~mm}$ & $\mathrm{NZ}$ & $21 \mathrm{~mm}$ & $20 \mathrm{~mm}$ & $22 \mathrm{~mm}$ & $20 \mathrm{~mm}$ & $21 \mathrm{~mm}$ & $7 \mathrm{~mm}$ \\
E-15 & $14 \mathrm{~mm}$ & $8 \mathrm{~mm}$ & $20 \mathrm{~mm}$ & $23 \mathrm{~mm}$ & $20 \mathrm{~mm}$ & $16 \mathrm{~mm}$ & $16 \mathrm{~mm}$ & $7 \mathrm{~mm}$ \\
E-16 & $20 \mathrm{~mm}$ & $9 \mathrm{~mm}$ & $22 \mathrm{~mm}$ & $20 \mathrm{~mm}$ & $23 \mathrm{~mm}$ & $22 \mathrm{~mm}$ & $20 \mathrm{~mm}$ & $\mathrm{NZ}$ \\
E-18 & $21 \mathrm{~mm}$ & $\mathrm{NZ}$ & $24 \mathrm{~mm}$ & $25 \mathrm{~mm}$ & $21 \mathrm{~mm}$ & $18 \mathrm{~mm}$ & $18 \mathrm{~mm}$ & $9 \mathrm{~mm}$ \\
\hline
\end{tabular}

Note: $\mathrm{S}=$ Streptomycin; $\mathrm{E}=$ Erythromycin; $\mathrm{G}=$ Gentamycin; $\mathrm{CH}=$ Chloramphenicol; $\mathrm{CI}=$ Ciprofloxacin $; \mathrm{CO}=$ Co-trimethoxazole; $\mathrm{AZI}=$ Azithromycin; $\mathrm{NV}=$ Novobiocin

The study was conducted to investigate the prevalence of Escherichia coli in freshwater fish particularly in Tilapia (Oreochromis niloticus) and Mrigal (Cirrhinus mrigala) in Sylhet, Bangladesh.

In this study, with the nutrient broth turbid, black centered colony with metallic sheen was observed in EMB agar. The present results similar to the findings of the Zinnah et al. (2007) and Sarba et al. (2019) presumptively recognized E. coli where they found in an EMB agar a greenish-black colony along with a metallic sheen. Same results were also found by some other 
authors (Buxton and Fraser, 1977; Freeman, 1985; Jones, 1987) whereas characteristic features of $E$. coli such as gram-negative, pink color, small rodshaped were noticed in gram's staining as well as hanging drop technique (Cowan, 1985) in which all the isolates showed motility. At the same time, the study possess the similar findings of Zinnah et al. (2007), Sarba et al. (2019), and Buxton and Fraser (1977) where the yellow slant revealed from the TSI agar slant with no hydrogen sulphide production. E. coli was confirmed by several biochemical tests were according to the Ali et al., (1998).

Table 3. Standard clear zone diameters for Enterobacteriaceae

\begin{tabular}{llll}
\hline \multicolumn{1}{c}{ Name of the antibiotics } & \multicolumn{3}{c}{ Zone diameter (mm) } \\
\cline { 2 - 4 } & Resistant & Intermediate & Sensitive \\
\hline Azithtromycin (AZI) & $\leq 13$ & $14-17$ & $\geq 18-$ \\
Ciprofloxacin (CI) & $\leq 15$ & $16-20$ & $\geq 21$ \\
Gentamycin (G) & $\leq 12$ & $13-14$ & $\geq 15$ \\
Erythromycin (E) & $\leq 13$ & $14-22$ & $\geq 23$ \\
Co-Trimoxazale (Sulpha/ & $\leq 10$ & $11-15$ & $\geq 16$ \\
Trimethoprim) (CO) & & & \\
Streptomycin (S) & $\leq 13$ & $14-20$ & $\geq 21$ \\
Chloramphenicol (CH) & $\leq 12$ & $13-17$ & $\geq 18$ \\
Novobiocin (NV) & $\leq 11$ & $12-15$ & $\geq 16$ \\
\hline
\end{tabular}

Table 4 Antimicrobial susceptibility pattern of $E$. coli isolated

\begin{tabular}{|c|c|c|c|c|c|c|c|}
\hline \multirow[t]{2}{*}{$\begin{array}{c}\text { Name of } \\
\text { Antibiotics }\end{array}$} & \multirow{2}{*}{$\begin{array}{c}\text { Antibiotic } \\
\text { conc. } \\
(\mu \mathrm{g} / \text { disc) }\end{array}$} & \multicolumn{3}{|c|}{$\begin{array}{l}\text { Sensitivity pattern of } \\
\text { isolated } E \text {. coli strains }\end{array}$} & \multicolumn{3}{|c|}{$\begin{array}{c}\text { Sensitivity pattern of } E \\
\text { coli ATCC strain }\end{array}$} \\
\hline & & $\% \mathrm{R}$ & $\% \mathrm{I}$ & $\% \mathrm{~S}$ & $\% \mathrm{R}$ & $\% \mathrm{I}$ & $\% \mathrm{~S}$ \\
\hline Streptomycin & 10 & - & 75 & 25 & - & - & 100 \\
\hline Erythromycin & 15 & 81.25 & 18.75 & - & 100 & - & - \\
\hline Gentamycin & 10 & - & - & 100 & - & - & 100 \\
\hline Chloramphenicol & 30 & - & - & 100 & - & - & 100 \\
\hline Ciprofloxacin & 5 & - & 25 & 75 & - & - & 100 \\
\hline Co-trimethxazole & 25 & - & 12.5 & 87.5 & - & - & 100 \\
\hline Azithromycin & 30 & - & 18.75 & 81.25 & - & - & 100 \\
\hline Novobiocin & 30 & 87.5 & 12.5 & - & 100 & - & - \\
\hline
\end{tabular}

These days, antimicrobial resistance became a worldwide matter of concern (Islam et al. 2016 and Miles et al. 2006). In country like Bangladesh, the issue of multi-drug resistant strain of $E$. coli is constantly raised due to the abuse of antibiotics (Islam et al., 2016). Although this finding was found to be similar with the many past studies, the incident was increased in food as well as human beings by several factors such as use of non-selective antibiotics with insufficient knowledge and at the same time carelessness towards the disease. In the present study, the prevalence, pattern of antibiotic sensitivity of $E$. coli in fish were examined. 
Spreading of the drug-resistant bacteria in the sewage and surface water occurred due to the release of human, animal, and bird fecal. Under some defined physicochemical and biological conditions, the resistant E. coli strains interchange R-plasmids to susceptible strains of E. coli (Rahman, 2008). When the environment get contaminated with the drug-resistant $E$. coli, human as well as animals face difficulties in the treatment after getting the infection (Joseph et al., 1979).

Multiple-drug (Erythromycin and Novobiocin) resistance was seen in all the strains and there is a common resistance pattern for antibiotics used among the strains. The mechanism for the spread of antibiotic resistance must be considered seriously like this present study. It is an alarming sign that the percentages of sensitivity towards all the randomly selected six antibiotics werenot satisfactory. From all of these antibiotics, Erythromycin (E) and Novobiocin (NV) were found unable to inhibit bacterial growth so that we cannot use them for the treatment of various diseases caused by E. coli from freshwater fish. At present, the possible reason of this high incidence of multidrug resistance is the non-selective use of antibiotics. With time, this might be taking the place of drug-sensitive organisms from the antibiotic saturated environment(Jawetz et al., 1984).

Resistance to Erythromycin is becoming a serious clinical problem (Mycek et al., 2000). In this study, $E$.coli was found the height resistance to the Erythromycin (81.25\%) while Al-Ghamdi et al., (2001) found E. coli isolates from layer and broiler source resistance to Erythromycin (87.4\%).

$E$. coli is a common pathogen isolated from fish meal and fish farming water (Oliveira et al. 2017 and Ristoriet al.2007), and play an important role in economic losses among the fish industry. As E. coli is highly pathogenic and cause diarrhoea (Sousa, 2006), so special care and further investigation are required to tackle this situation. Moreover, it is well evidence that $E$. coli causes food poisoning and food spoilage (Ekici et al. 2019). Therefore, the present study was performed to isolate and confirmed the presence of $E$. coli in freshwater fish by using various methods. From this study, it appears that $E$. coli collected from freshwater fish samples have some differences in antibiotic sensitivity patterns. Therefore, further study should include a wide variety of molecular tests with a large number of freshwater fish samples to see the difference and variation between them to reach a conclusive finding.

\section{LITERATURE CITED}

ALI, M. Y., RAHMAN, M. T., ISLAM, M. A., CHOUDHURY, K. A. and RAHMAN, M. A. 1998. Characteristics of E. coli isolates of human and animal origin. Progressive Agriculturist.9: 221-224. 
AL-GHAMDI, M. S., AL-MUSTAFA, F. EL-M. Z. H., FAIZ, M. and AL-RAMAHAN, M. 2001. Bacterial organism isolated from healthy chicken in the eastern province of Saudi Arabia and their pattern of resistance to antimicrobial agents. Scient J King Faisal Univ. 2: 113-126.

RAHMAN, M., RAHMAN, B. M. and RAHMAN, B. 2008.Antibiogram and Plasmid Profile Analysis of Isolated Escherichia coli from Broiler and Layer. Research Journal of Microbiology, 3: 82-90.

ASAI, Y., MURASE, T., USAWA, R., OKITSA, T., SUZUKI, R., SATA, S., YAMAI, S., TERAJIMA, J., IZUMUJA, H., TAMURA, K., and WATANABLE, H. 1999. Isolation of Shiga toxin producing E.coli0157:H7 from salmon roe associated with outbreak in Japan. Japan, 1998, and a molecular typing of the isolates by pulsed-field gel electrophoresis. J. Jpn. Assoc. Infect. Dis.73: 20-24.

ASSEFA, A. and ABUNNA, F. 2018. Maintenance of Fish Health in Aquaculture: Review of Epidemiological Approaches for Prevention and Control of Infectious Disease of Fish. Hindawi Veterinary Medicine International. ID 5432497: 10.

AYUlO, A. M., MACHADO, R. A., and SCUSSEL, V. M. 1994. Enterotoxigenic E.coli from the southern region of Brazil.Int. J. Food.Microbiol. 24:171-178.

BHUIYAN, A. L. 1964. Fishes of Dacca. Asiatic Soc. Pakistan. 13: 28.

BUXTON, A. and FRASER, G. 1977. Animal Microbiology.Escherichia coli.Black well Scientific Publications. Oxford, London, Edinburg, Melbourne. 1: 94-102.

CAPPUCCINO, J. G. and SHERMAN. N. 2007. A Laboratory Manual. ISBN-10: 0805325786 | ISBN13: 9780805325782 .

CLAUCAS, I. J. and WARD, A. R. 1996.Post-harvest Fisheries Development: A Guide to Handling, Preservation, Processing and Quality. Charthan Maritime, Kent ME4 4TB, United Kingdom.

COHEN, J. and SHUVAL, H. I. 1973. Coliform, fecal coliform and fecal streptococci as indicators of water pollution. Water Soil Pollution. 2: 85-95.

COWAN, S. T. 1985. Cowan and Steel's Manual for Identification of Bacteria. 2nd Edn., Cambridge University Press, Cambridge, London.

DUTTA. C., SAHA, D., PANIGRAHI A. K. and SENGUPTA, C. 2010. The occurrence of Escherichia coli in fish samples isolated from different ponds of Nadia District, West Bengal, India. Internet Journal of Food Safety, Vol.12, 2010, p.181-186.

EISENSTEIN, B. and ZALEZNIK, D. 2000. "Enterobacteriaceae" in Mandel, Douglas, \& Bennett's Principles and Practice of Infectious Diseases, Fifth Edition, Chap. 206: 2294-2310.

EKICI, G. and DUMEN E. 2019.Escherichia coli and Food Safety. Book chapter from The Universe of Escherichia coli .DOI: 10.5772

EZE, E. I., ECHEZONA, B. C. and UZODINMA, E. C. 2011. Isolation and identification of pathogenic bacteria associated with frozen mackerel fish (Scomberscombrus) in a humid tropical environment. African Journal of Agricultural Research.6(7): 1918-1922.

FRED, C. and TENOVER. 2006. Mechanisms of antimicrobial resistance in Bacteria. Am $J$ of Medicine.119 (6A): S3-S1 0. 
GRIFIN, PATRICIA and TAUXE, R. 1991. "The Epidemiology of Infections caused by Escherichia coli O157:H7, other Enterohemorrhagic E. coli, and the Associated Hemolytic Uremic Syndrome," Epidemiologic Reviews. 13(1): 60-98.

HANSON, S., AUSTIN, B. and AUSTIN, D. A. 2008.Bacterial fish pathogens, Diseases of farmed and wild fish. Springer-Praxis Publishing, Ltd., United Kingdom.

HASTEIN, T., HJELTNES, B., LILlEhAUG, A., UTNE SKARE, J., BERNTSSEN, M., and LUNDEBYE, A. K. 2006. Food safety hazards that occur during the production stage: challenges for fish farming and the fishing industry. Rev. Sci. Technol. 25(2): 607-625.

HUSSAIN, M. G. 2009. A future for the tilapia in Bangladesh. AQUA Culture Asia Pacific Magazine.

HUSS, H. H. 1997. Control of indigenous pathogenic bacteria in sea food. Food control. 8 (2): 91.

ICMSF (International Commission on Microbiological Specifications for Foods). 2002. Microorganisms in Food 7. Microbiological Testing in Food Safety Management.Kluwer Academic/Plenum, NY.

ISLAM, M. R. and MOKTADIR, A. A. 2016.A study on the prescribing pattern of antibiotics in rural area of Bangladesh.JIPBS. 3(4): 133- 138

JOSEPH, S. W., DAIly, O. P., HUNT, W. S., SEILDER, R. J., Allen, D. A. and COLWELl, R. R. 1979.Aeromonas primary wound infection of a driver in polluted waters. J. Clin. Microbiol. 10: 46-49.

LEE, M. D. and MARKS, M. D. 2009. Identification and typing of Vibrio anguillarum: a comparison of different methods. Syst Appl. Microbiol. 18: 285 - 302.

LEUNG, T. L. F. and BATES, A. E. 2013. More rapid and severe disease outbreaks for aquaculture at the tropics: Implications for food security. Journal of Applied Ecology. 50(1): 215-222.

LEY, A. N., BOWERS, R. J. and WOLFE, S. 1988.Indoxyl- $\beta$-glucuronide, a novel chromogenic reagent for the specific detection and enumeration of Escherichia coli in environmental samples. Can. J. Microbiol. 34: 690-693.

MANDAL, S. C., HASAN, M., RAHMAN, M. S., MANIK, M. H., MAHMUD, Z. H. and ISLAM, M. S. 2009. Coliform Bacteria in Nile Tilapia, Oreochromisniloticusof Shrimp-Gher, Pond and Fish Market. World Journal of Fish and Marine Sciences. 1 (3): 160-166

MANNA, S. K., DAS, R.and MANNA, C. 2008. Microbiological quality of finfish and shellfish with special reference to shiga toxin -producing Escherichia coli O157.J. Food. Science. 73(6): 283-286.

MILES, T. D., MCLAUGHLIN, W. and BROWN, P.D. 2006. Antimicrobial resistance of Escherichia coli isolates from broiler chickens and humans. BMC Vet Res. 2(7).

MITSUDA, T., MUTO, Y., ITO, A. and YOKOTA, S. 1998. Epidemiology study of a food borne outbreak of enterotoxigenicE.coli0157:H7 by pulse field gel electrophoresis and randomly amplified polymorphic DNA analysis. J. Clin. Microbiol. 36: 652-656.

MYCEK, M. J., HARVEY, R. A. and CHAMPE, P. C. 2000.Lippincotts Illustrated Reviews. Pharmacology, 2nd Edn.,Lippincotts Williams and Wilkins. 2: 311-320. 
OLIVEIRA, R.V., OLIVEIRA, M.C. and PELLI, A. 2017. Disease Infection by Enterobacteriaceae Family in Fishes: A Review. J. Microbiol Exp. 4(5): 00128

PETERSEN, J. and MCLAUGHLIN. S. 2016. Laboratory Exercises in Microbiology: Discovering the Unseen World Through Hands-On Investigation. City University of New York (CUNY) CUNY Academic Works.

RAHMAN, A. K.A. 1985. Introduction of Exotic Fishes in Bangladesh. Fisheries Research and Training Centre, (booklet).DOF.Chandpur, Bangladesh: 15.

RISTORI, C.A., IARIA, S.T., GELLI, D.S., and RIVERA, ING. 2007. Pathogenic bacteria associated with oysters (Crassostrea brasiliana) and estuarine water along the south coast of Brazil. Int $J$ Environ Health Res. 17(4): 259-269.

SARBA, E. J., KELBESA, K. A., BAYU, M. D., GEBREMEDHIN E. Z., BORENA, B. M. and TESHALE, A. 2019. Identification and Antimicrobial Susceptibility Profile of Escherichia Coli Isolated From Backyard Chicken in and Around Ambo, Central Ethiopia. BMC Veterinary Research.15(1):85.

SCHWARZ, V. 1984.A clinical companion to biochemical studies (second edition). W H Freeman, New York.162. ISBN 0-7167-1601-1

SHAFI, M. and QUDDUS, M. M. A. 1982.BangladesherMatshawSampod (in Bengali).Bangla Academy.Dhaka.72-73.

SOLIMAN, M. K., KHALIL, R. H., SAAD, T. T., EL-GAMAL M. H. L. and GEBRIL, A. E. 2010.Isolation and Identification of E. coli from Cultured Freshwater Fish. Journal of the Arabian Aquaculture Society. 5(1): 19-34.

SOUSA, C. P. 2006. The Versatile Strategies of Escherichia coli Pathotypes: A Mini Review. Journal of Venomous Animals and Toxins including Tropical Diseases.12(3): 364

TEOPHILO, G. N., AUS - FERNANDES VIERIA, R.H., RODRIGUEZ, P. and MENEZES, F.G. 2002. E. coli isolated from seafood: Toxicity and plasmid profile. Int. Microbial. 5:11-14.

THAMPURAN, N., SURENDRARAJ, A., and SURENDRAN, P. K. 2005. Prevalence and characterization of typical and atypical Escherichia coli from fish sold at retail in Cochin, India. J. Food Prot. 68(10): 2208-2211.

THATCHER, F. S. and CLARK, D. S. 1973. Microorganisms in Food: Their Significance and methods of enumeration. J. Royal Soc. Promo. Health Com. Count. 90(2): 120.

VIEIRA, M. A., ANDRADE, J. R. C. , TRABUlSi, L. R., ROSA, A. C. P. and DIAS, A . M. G. 2001. Phenotypic and genotypic characteristics of $E$. coli strains of non enteropathogenic serogroups that carry EAE and lack the EPEC adherence factor and Shiga toxin DNA probe sequence. $J$ .Infect. Dis .183: 762-772.

ZINNAH, M. A., BARI, M. R., ISLAM, M. T., HOSSAIN, M. T., RAHMAN, M. T., HAQUE, M. H., BABU, S. A. M., RUMA, R. P. and ISLAM, M. A. 2007. Characterization of Escherichia coli Isolated from Samples of Different Biological and Environmental Sources. Bangl. J. Vet. Med. 5 (1 \& 2): 25-32.

(Manuscript received on 27 May, 2020 revised on 27 August, 2020) 